\title{
A SURVEY OF TARGET INDUSTRIES
}

\author{
Daniel K. Lee*
}

\begin{abstract}
This paper surveys the literature in the area of target industries identification. It also surveys two important methods-screening approach and simultaneous approach-of target industries analysis, concentrating on five major articles along with other studies, in terms of methodologies, applied regions, and data requirements. Empirical applications to the Pascagoula-Moss Point Metropolitan Statistical Area highlight the differences in the two approaches. Empirical results, as well as theoretical aspects, recommend the simultaneous over the screening method. Furthermore, this paper examines the recent development in target industries research and clarifies the basic issues and future research needs. Issues discussed are (1) weighting method, (2) dynamic analysis, and (3) model validation.
\end{abstract}

\section{INTRODUCTION}

Until recently, target industries identification was largely ignored in the economics literature of industrial location research. Only five papers, to my knowledge, have been published in refereed journals in this area: Sweet (1970a, 1971); Bohm, Herzog, and Schlottmann (1983); Thornton (1984); and Lee (1987). However, a significant number of studies have emerged on the target-industries model during the last few years. This development has been marked by an increased demand for research in this area.

Not surprisingly, little attention has been directed toward the survey of target industries research. The purpose of this paper is to survey the literature in the area of target industries. More importantly, the paper attempts to examine the recent developments in the area, to clarify the basic issues, and to summarize what regional economists or scientists can do to improve their target industries models.

Section II describes two major approaches of target industries analysesscreening and simultaneous approaches-and cites major works in these areas, concentrating on the five refereed articles' works. Applications of both approaches and discussion of them are given in Section III. Section IV reviews the recent developments in the area. In this section, three issues-weighting method, dynamic analysis, and model validation-are discussed.

\footnotetext{
*Director of Economics, Center for Policy Research and Planning, Board of Trustees of Mississippi State Institutions of Higher Learning.
} 


\section{METHODOLOGIES}

Target industry models, created to make effective matches between an area's resources and potential industries, have recently come into wide use in the economic development and regional science communities. The target industry approach examines an area's advantages in labor availability and costs, industrial linkages, industry growth rates, natural resources, land prices, and other related variables with regard to their effect on industry location. Then, the target industry modeler chooses industries best suited to the area, with a careful eye on those specific advantages. Industries such as wood and paper products manufacturing, for example, would probably try to locate in a geographic area with generous timber resources.

In the realm of target industries models, several specific techniques have been developed; the most commonly used approaches include the simultaneous method and the screening method. The simultaneous method ranks all potential industries simultaneously, considering all variables judged to be important. The screening approach, on the other hand, separates industry prospects into groups based on their acceptability or unacceptability. If an industry fails to satisfy even one condition of the test, the industry will be dropped from the list of prospects. Because both target industry approaches show some weaknesses, analysts in more recent years have sought to combine the two approaches using differential weights to compensate for a variation of location decision variables across industries. Other modifications to the target industry method have been suggested to minimize the rigid and unchanging nature of earlier models.

Regional development is concerned with an issue broader than that of target industries. The former deals with "levels and changes over time in population, work force, capital-labor ratios, and in rates of retum to land, labor, and capital in geographically bounded, generally contiguous territories" (Leven 1985, 569). Target industries research presents one element of such a broad issue. According to Herzog and Schlottmann (1991), research on industrial location determinants has two distinct approaches. "Regional science emphasizes traditional locational determinants such as regional markets and transportation access ..... By contrast, the public finance literature most often concerns local public sector initiatives as locational determinants ...." (Herzog and Schlottmann 1991, 1-2). Target industries research does not investigate such locational determinants; it utilizes the results of industrial location studies in designing the model and selecting important variables in the model. The development of target industry techniques has depended upon and become an integral part of industrial location and regional development policy; thus, the target industry approach is but one aspect 
of regional development and investigates target industries in a specific region, assuming no changes in regional economic structure.

The need for carefully focused economic development efforts has increased as the competition for new industry has been heightened. A broad spectrum of regional development policy tools has developed to make the industrial location process more scientific and effective. Target industry information has developed into an important tool in industrial location decisions, but its significance should not be limited to identifying industries best suited to a particular location. Instead, the target industry approach should be viewed as a tool with broader use in outlining for a developer the region's advantages and disadvantages in attracting industry. In other words, economic developers can become more efficient at making their area attractive if they have specifically identified that area's weaknesses and strengths. Not only will that allow an area to attract well-suited industries, but it will also help the area improve its attractiveness to industry, at least in those areas over which it exercises some control. Besides its usefulness to industrial developers to choose and attract appropriate industries, target industry modeling can also be used by industry to examine potential sites for expansion or for location of additional research centers, distribution centers, and other facilities.

In recent years, target industry analysis has become important in the development of new and expanded industries, as it has been used by decisionmakers both in economic development positions and within industries seeking additional locations. While target industry approaches themselves serve to narrow the field in industrial development, their use is actually very broad-based as a tool for regional development and industrial interests.

\section{Screening Approach}

The most popular method for targeting industries is called the screening approach, which eliminates the candidate industries that do not fit the region through screening tests and identifies the target industries. For example, if an industry requires skilled labor and the regional labor force is unskilled, then that industry will be eliminated from the target industries list. In many cases, a series of screening tests is conducted and, finally, the industries that fit the region or desire to locate in the region are identified from many candidate industries. Table 1 offers a summary of methodologies of and data analyzed in target industries studies.

Sweet's pioneer works $(1970 \mathrm{a}, 1971)$ laid the foundation for target industries research. Sweet (1970a) notes that the traditional "shotgun" approach to industrial development has been proven ineffective and expensive for most organizations. A research program can help make development efforts more effective. A critical first step in this program is the identification of objectives for area industrial 
development. Some of the targeted objectives have included higher wages and employment, greater employment stability, effective use of the existing labor pool, increased tax receipts, reduced out-migration, effective use of industrial linkages, and upgrading of types of industries in the region. After the goals have been pinpointed, resources available to new or expanding industries must be evaluated. Resources are the major factor in an area's comparative advantage; those resources can include natural resources, human resources, institutional resources, the existing industrial structure, industrial financing, transportation, services, and others. Industrial linkage-the flow of materials between establishments and markets-must be included in this process. After this analysis has identified the area's comparative advantages, the development organization may begin to list industries that match those advantages. The results of input-output studies can be used in an industrial development program to forecast output, evaluate exports, determine import substitutions, and identify intermediate exports and linkages. Each industry identified as a candidate for development in the region must be screened. Sweet suggests that an analysis be conducted on the basis of projected industry growth rates, wage levels, labor intensity, markets served, industrial linkages, labor skill level and materials required, and port orientation.

Thornton's (1984) study on target industries offers methods to identify and rank industries appropriate to an area. Good prospects for target marketing include industries that show strong historical national and regional growth in employment, number of establishments, and value of shipments, or that possess other characteristics that make them obvious candidates for future industrial development. A data base to identify growth industries can be built using statistical data bases already put together by consulting or research companies and then employing statistical series showing growth trends. Specifically, Thornton's study suggests that industries be considered potential target industries only if growth rates in employment, establishments, and shipments/sales are at least one standard deviation above the mean. She further suggests that after growth industries have been defined, they should be reviewed in the "locational fit analysis." In that analysis, the developer must define locational factors in the industry, assess the community's comparative resource advantages and disadvantages, and conduct a fit analysis blending those two components. Information needed for the locational fit analysis may include such items as labor costs and availability, transportation, proximity to markets and suppliers, energy costs, water supply, lifestyle, urbanization, tax climates, industry size, and intuitive appeal. The second portion of Thornton's fit analysis involves assessing the community's comparative resource advantages and disadvantages for each of the factors listed above. This assessment can be completed by conducting a survey of industries in the region that 
have recently expanded in or relocated to the area. However, the industrial structure of neighboring regions or regions with similar resource attributes is not considered as a method for identifying target industries that are not currently located in the region. This factor is one of the weak points of the study. Matching the industry's requirements with the community's strengths, Thornton says, will result in a list of industries most appropriate to the area.

Many other studies, such as Battelle Columbus Laboratories (1979), Tennessee Valley Authority (1982), Brown (1988), Farahbod and Kaminarides (1990), Minshall and Wright (1990), and Morton (1990), belong to the screening approach. Maki and Baxter (1990) identified target industries for the regional city focusing on export expansion, import substitution, and neighborhood development. Table 1 lists the methodologies and data requirements specific to each of these studies.

\section{Simultaneous Approach}

Another typical approach to target industries identification is a simultaneous approach, which ranks the potential industries simultaneously using a computerized model that examines all variables judged to be significant in industry location decisions. Sweet (1971) identifies a community's industry potential, defined as matching up a community's resources with specific industry requirements and then identifying prospects. Generally, he states, industry location decisions are twofold, including the identification of desired regions and selection of specific sites. Sweet discusses a computer model that is suitable for the portion of the process in which the region is identified. Use of a computer model is intended to rank potential industries for a selected set of regions. In this process, four locational factors were used, including markets, suppliers, transportation, and labor force. In addition, those four categories can be divided into more detailed subcategories. In his model, each industry is analyzed on 15 characteristics, which include: industry's orientation to intermediate and consumer markets; raw material requirements; intermediate manufactured products and services; orientation to shipping of products by rail, highway, or water; and requirement for workers of various skill levels. Similarly, each region is evaluated on the basis of several factors, such as intermediate and consumer market potential; suppliers available; distance to nearest interstate highway, rail line, and port; and available labor force by education (skill) level. These resources in the region are analyzed in terms of the specific industry being evaluated. After the two analyses have been completed, they can be compared to identify an industry's match to a specific region. In the computer model suggested by Sweet, a researcher can either evaluate one industry with a large number of regions or one region with a large 
TABLE 1

Methodologies and Data Features of the Target Industries Studies

Study (Year) Methodology/Objectives Applied Regions Data

\section{Screening Approach}

Sweet (1970a)* Screen matrix

Battelle Columbus Laboratories

(1) Industry screenin , (2) analysis of growth and shift, and (3) markets and supplies.

Tennessee Valley Authority (1982)

(1) Input supply linkages, (2) comparative advantage, and (3) historical location.

Thomton (1984)*

(1) Identification of growth industries and (2) industry evaluation matrix and assessment of area strengths and weaknesses.

Brown (1988)

Farahbod and Kaminarides (1990)

Minshall and

Screen matrix

(1) Performance evaluation and (2) location requirement evaluation.

\section{Screen matrix}

No application

State of Washington

Chattanooga

Economic Development Council area (ten counties in Tennessee, seven counties in Georgia, and two counties in Alabama)

No application

Southwest Virginia

Nonmetropolitan areas in northeast Arkansas

No application
(1) Projected industry growth rates, (2). wage levels, (3) level of labor intensity, (4) markets served (5) industrial linkages, (6) skill level of labor required, (7) material requirements, and (8) port orientation.

(1) Labor market, (2) energy, (3) transportation (4) land use, 5 interindustry linkages.

6) employment growh trends and shifts, (7) water transportation, (8) import/export and others.

(1) Wage levels, (2) regional markets, (3) growth potential, (4) location ability, (5) state/ transportation, (7) electricity availability/cost, (8) proximity to markets, $(9$ proximity to sup pliers, and'(10) region's historical employment.

(1) Industry growth rates,

(2) labor costs (3) labor availability, (4) transportation access, (5) proximity to markets (6) proximity to suppliers, (7) energy cost/ availability, (8) water supply, (9) lifestyle, (10) urbanization, (11) tax climate, and (12) industry size.

(1) National employment trends, (2) projected national employ-

ment levels and growth rates,

(3) projected Virginia employment levels and growth rates, (4) new plants and expansion in Southwest Virginia, (5) new plants and expansion in the rest of Virginia, (6) branch plants. (7) existing industries in Appalachia, (8) market linkages, and (9) industry concentration in Virginia.

(1) Historical and projected industry growth rates, (2) industry growth rates in the nongrowth rates in the non-
metropolitan areas of West South-Central region, and (3) input requirements.

(1) National and regional growth in employment and frowth (2) regional resources fims, (2) regional resources ness climate, local operating environment, comparative costs),

(3) market/supplier linkages,

(4) transportation, (5) labor force, (6) wage rates, (7) energy and utilities, and (8) sites and structures. 
TABLE 1 (Continued)

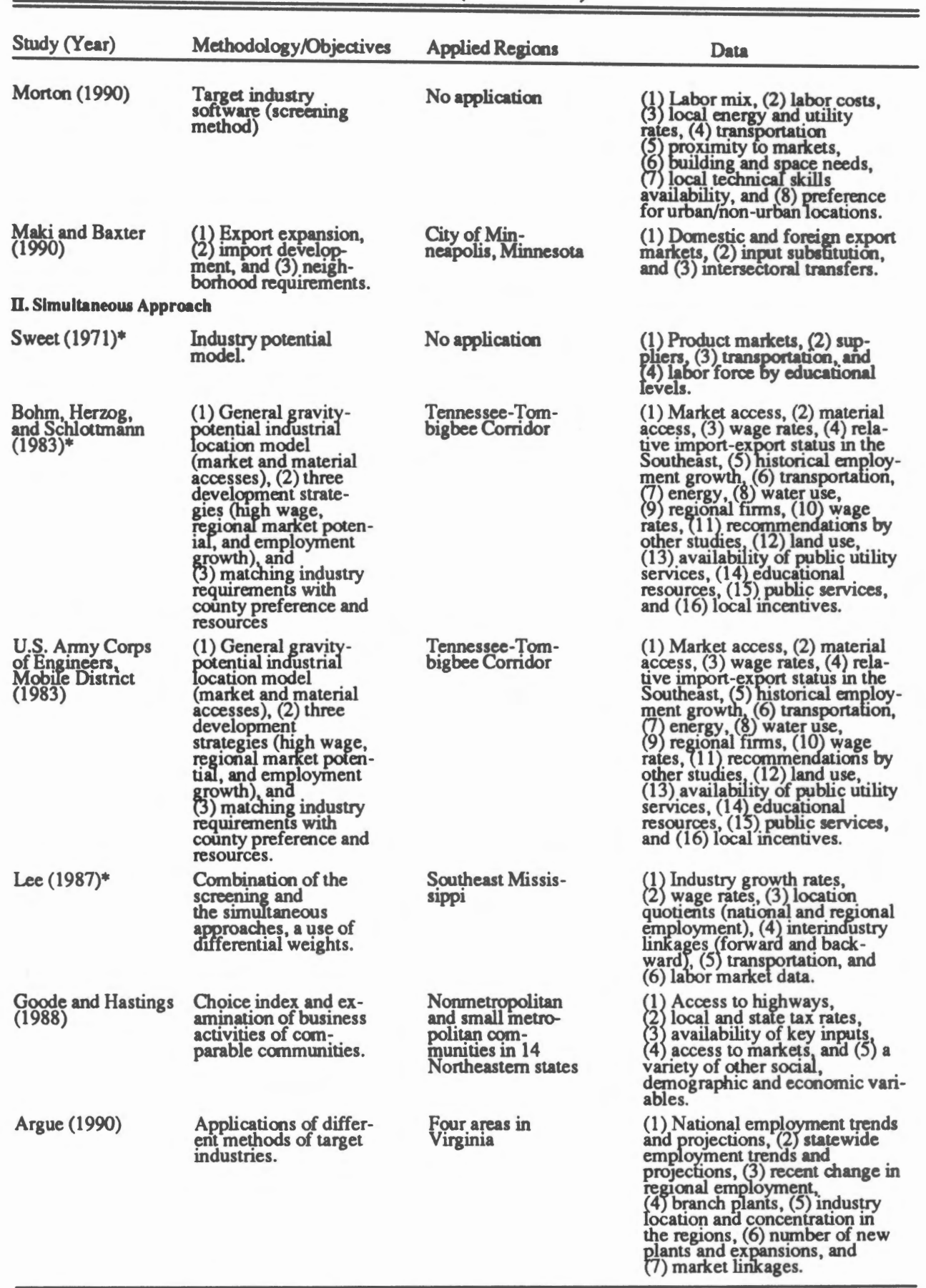

Note: *Indicates five papers that have been published in refereed joumals. 
number of industries. The model relies heavily on input-output data and shows the significance of input-output tables in identifying industry requirements and market and supplier linkages.

Bohm, Herzog, and Schlottmann (1983) discuss development of a methodology to identify manufacturing industries that are particularly well suited to location in the Tennessee-Tombigbee corridor. The authors' methodology is composed of three steps: developing a general gravity-potential industrial location model that gives an unconstrained ranking of industries on the basis of potential profitability; limitation of the selection process on the basis of three "industrial development strategies"; and modification of the selection process in the field based on matching of industry and county characteristics. The initial step brings out those industries that match the area most closely in terms of geographic location, especially the county's nearness to major suppliers and buyers. County wage rates are also a major component in this ranking. This first selection of counties is important because it identifies industries that would require the least inducement to locate in the area. In the second step, industrial development policy objectives can be introduced into the process, using strategies based on high wages, on regional market potential, and on employment growth. The authors' third step gives local development officials some initiative in molding the system to changing conditions in the area and to industries preferred by the officials.

Lee's (1987) paper, which includes the most thorough reporting of the literature on target industries, demonstrated a combination of the screening method and the simultaneous method. The paper provided a new approach that overcomes the disadvantages of each. First, he screened industries based upon three different scenarios: (1) growth rates, (2) wage rates, and (3) location quotients. The first two scenarios reflect regional economic development priorities and preferences, and the third considers the demand and supply situations of the industry's product in the area. Location quotients can provide simple but important insight to planners and policymakers. Then, the simultaneous method is applied to the industries that passed the initial screening test. Another feature of Lee's study is the use of differential weights; the study reads, "Differential weights are assigned to the various location factors in determining industrial rankings because the variables that influence location decisions vary across industries." This issue is discussed in the next section as a problem of the weighting method.

Reports by Sweet (1970b), the U.S. Army Corps of Engineers, Mobile District (1983), and Argue (1990) are the only known target industries studies using the simultaneous approach. Goode and Hastings' (1988) unique study applied an econometric model to predict the relative likelihood of potential industries locating in each community. Goode and Hastings compared the development potential of each specific community to other communities of the same class. 


\section{EMPIRICAL APPLICATIONS}

Three major types of approaches-the screening approach and two different types of simultaneous approaches-of target industries are applied to the Pascagoula-Moss Point Metropolitan Statistical Area (MSA) in Mississippi for numerical examples. The Pascagoula-Moss Point MSA is located in the southwest corner of Mississippi and covers all of Jackson County. A navy port and one of Mississippi's most industrialized areas, the MSA includes such major manufacturers as Ingalls Shipbuilding, Chevron U.S.A., and International Paper. Table 2 lists the top 15 target industries derived by (1) the screening approach, (2) the simultaneous approach with equal weights, and (3) the simultaneous approach with differential weights in the Pascagoula-Moss Point MSA. The equal weight method assumes that each location variable has an equal importance in industry location decisions; on the other hand, the differential weight method assumes that industry location decisions are different among industries. Therefore, the latter method assigns different weights on location variables as contrasted to the equal weight method, which considers all location variables equally. Industries reported in Column (1) are picked up from the study conducted by the Mississippi Research and Development Center (1977). The study employed a very simple screening method using variables such as industry growth rate, energy availability, geographic location, labor force, natural resources, and transportation network. The simultaneous approach described by Lee (1987) was applied; the top 15 target industries are reported in Column (2) under the equal weight method and in Column (3) under the differential weight method.

Industries in petroleum products (SIC 29) and food products (SIC 20) are eliminated when the screening approach is applied, even though these industries actually have strong locational advantages in the MSA. Elimination of the petroleum industries can be traced to a labor market mismatch, especially to a shortage of administrative and management, professional, and craft and repair labor in the MSA. Because the area has a mismatch in the labor market, the screening approach completely eliminates the petroleum industries. In other words, lack of fit by just one factor can penalize the area by entirely eliminating an industry from the target list. The geographic location factor became a problem for the food products industry because the MSA and the surrounding area lacked the large consumer market needed by the industry. Just as one factor prevented petroleum products industries from making the screening approach target list, one variable penalized the area in its suitability for the food processing industries. The strong availability of seafood and other food raw materials should mean that food processing is an important part of the coast's economy if there are no strong factors that prevent the industry from being a competitive one in the region, yet the 


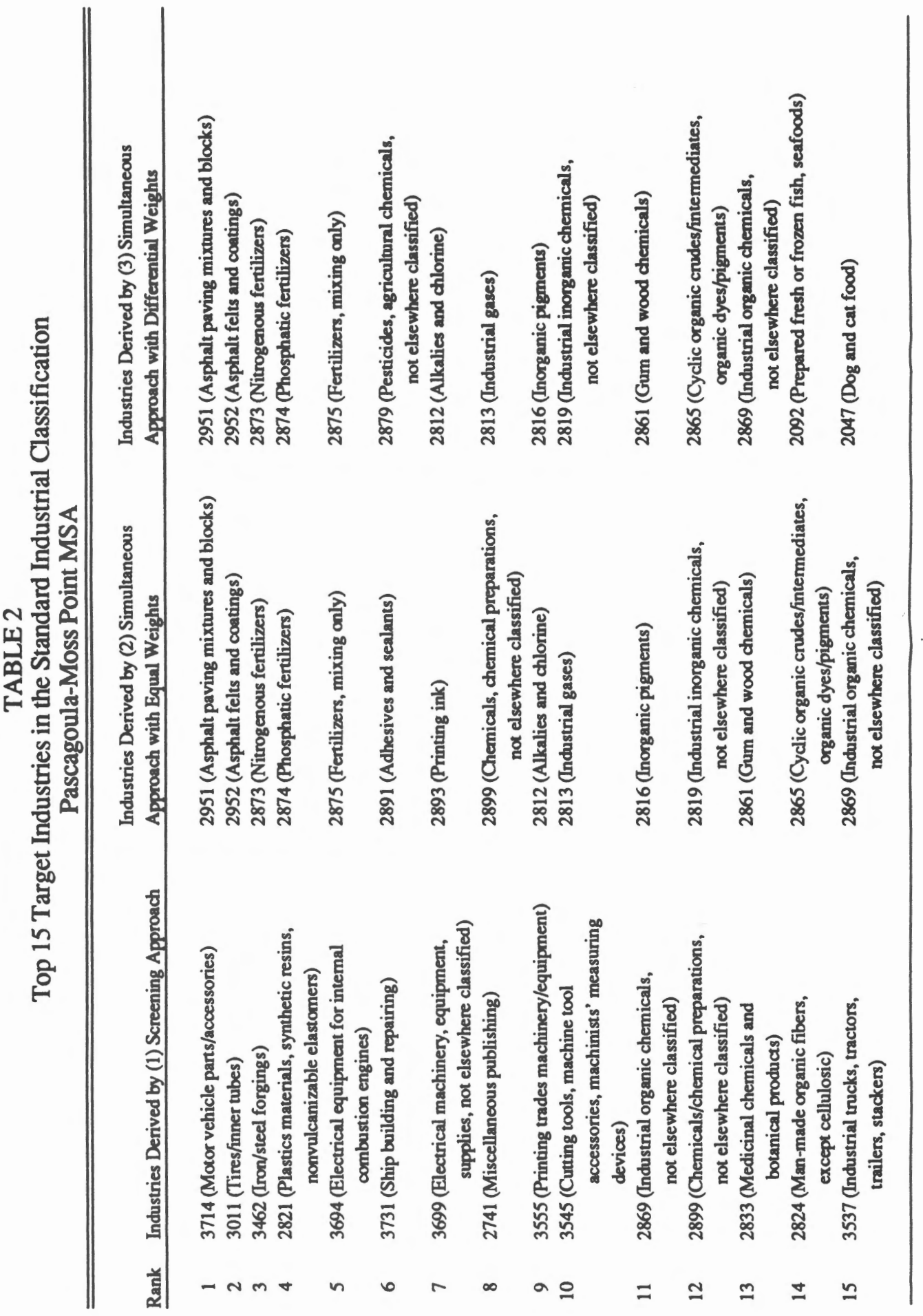


screening approach eliminated the industry from the target list. Again, the area is greatly penalized for failing to match up on one component, even though it satisfied other factors quite well. The nature of the screening approach can allow too much emphasis on one or two factors in the analysis, thus eliminating industries that could be very important to the area.

The variation in industries selected indicates a clear gap between the screening and simultaneous approaches. However, the differential method within the simultaneous category still captures target industries better than does the equal weight measure. One of the problems with the equal weight method is underlined by the elimination of the food processing industry when that method is used. In the equal weight method, product and supplier markets are given the same weight, although the supplier market is much more important to the food processing industry, particularly for canned and frozen foods. In the differential approach, though, more emphasis is placed on the important raw materials markets.

Use of either the equal weight or the differential weight simultaneous method yields the same five industries at the top of the target list: 2951, 2952, 2873, 2874, and 2875. When the screening approach is used, however, none of those industries even makes the list of the top 15, much less the top five. None of the top five industries chosen using the screening approach, on the other hand, is named by either simultaneous method. In fact, the target list of the MSA's top 15 industries, as chosen by the screening method, completely ignores the food processing and petroleum products industries. The equal-weight approach captures some of those industries, while the differential-weight method shows an even better fit for the area.

Empirical results, as well as theoretical aspects, recommend the simultaneous method over the screening approach. Within the simultaneous category, the differential weight method captures target industries more effectively than does the equal weight approach. Nevertheless, a simplification of the differential weight simultaneous approach would be required if policymakers and planners desire a simpler, easy-to-apply model because of the approach's sophistication and data requirements.

\section{RECENT DEVELOPMENT IN TARGET INDUSTRIES RESEARCH}

\section{Weighting Method}

One of the recent developments in the area of target industries identification involved the issue of weighting methods. Many studies described in Section II utilized an equal-weight method, or they were not systematic in weights. 
Lee (1987) developed the differential weights in measuring the "distance" between a region's resources and industry requirements. Since the factors that determine industrial relocation and expansion vary across industries and regions, the differential weights are more appropriate in a targeting process. Lee used Schmenner's (1982) results from a qualitative survey of business location decisions. Schmenner's study is one of only a few that investigate the different behaviors in location decisions among industries. Lee's empirical results demonstrate that a differential-weight method performs better than an equal weight method.

Lahr, Meszaros, and Stevens (1988) went further and proposed the use of the multiple-objective decision method for identifying target industries. They identified the line that is often drawn between industries' locational requirements and regional economic development priorities, and the three authors explored an extensive list of measures for targeting industries. The analytic hierarchy process, which is designed for making choices among discrete options, was chosen as the specific multiple-objective method. The method is very comprehensive and promising for target industries research. The disadvantages of this method are the huge amount of data needed for disaggregate sectors and the quantity of work that is required to gather priorities from many industries. Argue (1990) applied the analytical hierarchy process to four areas in Virginia.

\section{Dynamic Analysis}

Another recent development in the area of target industries research is the dynamic target industries model. Some studies suggest that the model should incorporate forecasts, rather than historical information, on regional and industry data; however, regardless of the source of the information, the model remains static and assumes the existing industry requirements and regional resources. In Lee's (1989) short report, an experiment on dynamic target industries was attempted. He insists that "consideration of an expected change of some portion of the economic structure in the future requires an adjustment to the target industries model." Using the simple screen matrix developed by Sweet (1970a), Lee estimated mid-term and long-term target industries for the state of Mississippi. The assumptions used to project target industries are a key part of the study. Although a broad change of the economic structure over time is considered, the most important single change is the shift in labor supply, based upon improvement of the region's education system, coupled with improved job training programs.

Recently, Lee and Ranck (1988) provided a theoretical structure for a dynamic approach to regional economic development analysis. In Lee and Ranck's article, a Markowitz optimal portfolio of industrial diversification was 
adopted as the policy objective, and optimal economic development policy over time was analyzed. They used state and local government fiscal policies-such as taxes, expenditures for education, economic development, and research and development-as policy variables and employment, income, or value added as state variables. Although the focus of their research is on regional industrial development, diversification, and policy altematives, the research does suggest an optimal economic structure and particularly an industry mix. Therefore, this kind of dynamic model could indicate what the dynamic target industries are for the region. The model would tell us which target industries change over time for the specific region. However, it should be noted that a construction of the dynamic model requires highly trained researchers and a tremendous amount of work, and this approach is probably beyond the regional policymakers' and planners' ability. Simplification of the model is required to be utilized widely among policymakers and planners. This issue would be an exciting area for future research in target industries research.

\section{Model Validation}

One of the major issues of target industries research is validation of the model. Because of its unverifiable nature, the validation issue has not been discussed in the literature. To be scientific, target industries identification cannot avoid the issue of how to determine the model's accuracy. Even if the target industries' list in the specific year matches with the industry mix in later years, it is difficult to determine whether the new industry mix is created by policymakers' and planners' efforts based on recommended target industries or whether the industry mix is generated by other economic forces.

One way to determine the validity of the model would be to investigate one region's changes in industry mix over time compared to changes in other regions with similar industry structure, location, size, and to changes in the national economy. Changes in industry mixes could be broken down into parts, isolating and investigating the effects of locational advantages of the region. Another direction the validation issue could take would be to compare industrial location studies, analyzed by econometric models, with target industry studies. This comparative analysis is another area of promise in future target industries research. One of the pitfalls in this area is the emphasis and dependence upon, as a way of model validation, the investigation of gaps between target industries and existing industries in the area. The majority of industries that are currently important in the area appear to have located in that specific area in part because of locational advantages. Yet, stressing existing industries would mean that industrial targeting could be simplified by attracting and encouraging additional industry of the same 
type that is found currently in the area. Such an approach would lead to maintenance of the status quo in an area's industrial structure.

Unfortunately, we still understand very little about methods of validating target industries models from a scientific viewpoint, which is certainly the weakest of the three issues (weighting method, dynamic analysis, and model validation) of target industries research frontiers. Until better methods of model validation are generated and tested empirically, this issue must remain open; the importance of model validation, though, requires that additional research continue in the future.

\section{REFERENCES}

Argue, D. A. "Improvements in Targeting Industries." Paper presented at the Southern Regional Science Association meetings, Washington, D.C., March 1990.

Battelle Columbus Laboratories. A Community Level Target Industry Identification Program. Columbus, Ohio: Battelle Columbus Laboratories, 1979.

Bohm, R. A., H. W. Herzog, Jr., and A. M. Schlottmann. "Industrial Location in the Tennessee-Tombigbee Corridor." The Review of Regional Studies 13 (1983): 28-37.

Brown, M. V. "Southwest Virginia Target Industry Study." Paper presented at the

Southern Regional Science Association meetings, Morgantown, West Virginia, April, 1988.

Farahbod, K., and J. S. Kaminarides. "Targeting Industries for Non-metropolitan Areas: An Industry Screening Approach." Paper presented at the Southern Regional Science Association meetings, Washington, D. C., March 1990.

Goode, F. M., and S. E. Hastings. "Northeast Industrial Targeting (NIT) and Economic Development Database (EDD) System." Paper presented at the Southern Regional Science Association meetings, Morgantown, West Virginia, April 1988.

Herzog, H. W., Jr., and A. M. Schlottmann. Industry Location and Public Policy. Knoxville, Tenn.: The University of Tennessee Press, 1991.

Lahr, M. L., J. R. Meszaros, and B. H. Stevens. "Using the Analytical Hierarchy Process to Weight an Extended Array of Measures for Targeting Industries for Regional Economic Development." Paper presented at the Southern Regional Science Association meetings, Morgantown, West Virginia, April 1988.

Lee, (D.) K. C. "Modeling Target Industries with Differential Weights."Papers of the Regional Science Association 62 (1987): 125-135. 
Lee, D. K. "Dynamic Target Industries for Mississippi." Center for Policy Research and Planning, Mississippi Institutions of Higher Leaming, June 1989.

Lee, D. K., and E. L. Ranck. "The Dynamics of Regional Industrial Development, Diversification, and Policy Alternatives." Paper presented in the American Economic Association Session on Regional Development and Industrial Structure at the Allied Social Science Association annual meetings, New York City, December 1988.

Leven, C. L. "Regional Development Analysis and Policy." Journal of Regional Science 25 (1985): 569-592.

Maki, W., and S. Baxter. "Industrial Targeting in Minneapolis Using IMPLAN." Paper presented at the North American Regional Science Association meetings, Boston, Massachusetts, November 1990.

Minshall, C. W., and C. J. Wright. "An Approach for Identifying Target Industries and Implementing a Focused Economic Development Program." Paper presented at the Southern Regional Science Association meetings, Washington, D. C., March 1990.

Morton, L. "Midwest Research Institute's Target Industry Software, Targets, and the MRI Targeting Process." Paper presented at the Southern Regional Science Association meetings, Washington, D. C., March 1990.

Mississippi Research and Development Center. Industry Fit Directory. Jackson, Miss.: Mississippi Research and Development Center, 1977.

Schmenner, R. W. Making Business Location Decisions. Englewood Cliffs, N.J.: Prentice-Hall, 1982.

Sweet, D. C. "The Systematic Approach to Industrial Development Research." AIDC Journal 5 (1970a): 21-32. . "Development and Application of An Industry Potential Model." Ph.D. diss., Department of Geography, The Ohio State University, 1970b. "Identifying Industry Potential." AIDC Journal 6 (1971): 71-76.

Tennessee Valley Authority. Targeting Industry Analysis for the Chattanooga Economic Development Council Area. Knoxville, Tenn.: Economic Development and Analysis Branch, 1982.

Thornton, L. W. "Targeting Industries for Economic Development." Economic Development Review 2 (1984): 23-28.

U.S. Army Corps of Engineers, Mobile District. Industrial Location in the Tennessee-Tombigbee Corridor, 1983. 